\title{
Enhancing The Calculating Estimation Skill of The Students of Grade VI in The Primary School
}

\author{
Goenawan Roebyanto \\ Elementary School Teacher Education \\ Universitas Negeri Malang \\ Malang, Indonesia \\ goenawan.roebyanto.fip@um.ac.id
}

\begin{abstract}
The 2013 elementary curriculum, 2017 revision suggests that estimated learning in class VI, hereinafter referred to as "estimation", is still limited to rounding activities. From the results of this study it was found that (1) in general, students have not been able to develop a certain approximate calculation, (2) students find it difficult to release their procedural knowledge before estimating calculations, because they are accustomed to proper calculations, (3) students in studying and exploring patterns of estimating arithmetic, need to be done in implementing the introduction of benchmarks to improve numeracy estimation skills. Whereas the variety to increase arithmetic estimation includes learning numeracy estimates related to whole numbers, fractions, and decimal numbers. Based on the results of the study, it was suggested to the math teacher to always ask students to estimate before calculating.
\end{abstract} school

Keywords- calculating estimation, benchmark, primary

\section{INTRODUCTION}

In daily life, there are many problems should be solved soon and finished fast. The problem-solving process does not always need algorithms based on the mathematics rule and does not need an appropriate answer, but it only needs the closer answer estimation. The estimating process is called estimation. Based on such case, Carlton and Fitzgerald [1] from their survey results state that more than $80 \%$ of all mathematics applications in daily life use estimation rather than the exact calculation. Meanwhile, the mathematics learning (in school) is dominated by the exact calculation. This case is definitely difficult for students to complete the problems related to the estimation if they have not known it well.

The questions below can be answered quickly if someone has the good ability in calculating estimation. For example: (a) Is my money of Rp. 15.000,- enough for photocopying 98 sheets that the fee per sheet is Rp. 145,-; (b) Is money of thirty thousand rupiahs enough for a Madam to buy $21 / 4 \mathrm{~kg}$ of sugar if its price is Rp. 12.750,- per kg; (c) which one resulting bigger between "5 $\square 90$ " and "96 $\square 94+91+90+$ 85 " ?. In calculating estimation the item of (a), (b) and (c), we will feel easy if there is a number becoming the basic reference that is called benchmark. Reys et al. [2] state that the benchmark is a very significant tool and beneficial in doing the estimation.

In addition, Walle, Van de J A. [3] state that the estimation ability is closely related to the mental computation skill, numeration concepts, and the real-world number sense. Most of the estimation is based on the use of "nice number" idea that is closely related to the number that will be computed. The nice number gives the possibility to do the mental computation. For example, 30 marbles with its price are Rp. 98,- per item can be estimated by using 100 to represent 98 rupiahs. Now, 30 is multiplied by 100 is a mental computation skill. If students do not have such ability, the use of 98 is not really helpful.

The students also face some problems that cannot be solved in learning mathematics. Whereas, solving a math problem is the best way to improve someone's mathematics skill, particularly for those who want to take a role in developing mathematics and its use [4]. In term of problemsolving (mathematics), estimation has an important position in solving the problem quickly. For more information, the position of estimation in problem-solving is presented as follow.

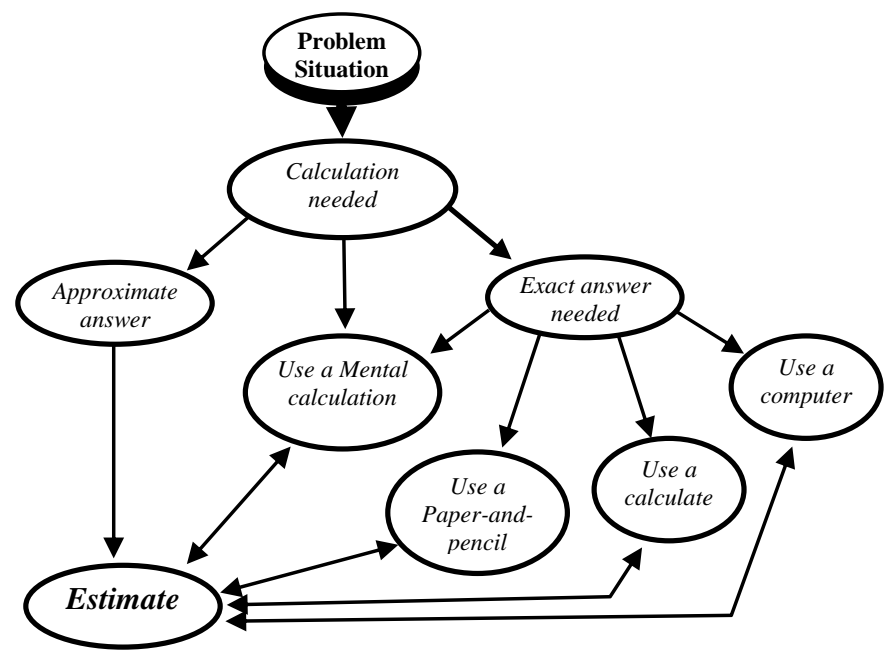

Fig. 1. Schematic scheme of the problem in daily activity. Adopted from NCTM Commission on Standards for School Mathematics, Walle, J. A Van de.: 2013 [3]

From the Fig.1 above, it is clear that although estimation is needed in the approximation answer, it also has a correlation to (a) mental calculation, (b) paper and pencil calculation, (c) calculator, (d) computer. Calculating estimation is one of the calculating tools beside calculator; it is a kind of mental calculation and algorithms using paper and pencil [5]. Every calculation tool is beneficial and efficient in a certain context. The use of a calculator is effective if the intended answer is appropriate, accurate in a brief time. The "logic" of the calculation results got by using calculator can be detected if someone has estimation skill. The error in entering the calculated items (wrongly press the digit button of the calculator) could be the reason for such a phenomenon. 
In addition, Walle [3] states that one of the ways to indicate that estimation is not intended to one right answer is by asking the students to determine whether the result of the certain calculation is more or less than certain mark. For example: Is $847+174$ more or less than 1000 ?" Besides, we can also provide some forms of calculation and an intended number. For example: which one of these choices that the result is about 1.500 : (a) $976 \times 15,6$; (b) $156 \times 9,76$; (c) 156 x 97,6 ?". Based on the explanation above, we can say that flexibility in concept and operation (calculation) is needed to estimate well.

The flexibility in understanding the concept and calculation operation is crucial since only by learning and using algorithms the students will be bound by the use of paper and pencil without description and imagination about the number. This case may cause difficulty in estimating and predicting one kind of calculation even in detecting the error in it without repeating the calculation process from the first until the end. For the problem of multiplication such as:"429 x $2=658$ ", the student that has estimation skill (informal method) can get quickly that the answer is "wrong" [6]. This case is because the answer is not meaningful at all (400 x 2 results 800 , how about $29 \times 2$, therefore the result must be more than 800 ). On the contrary, the students that cannot do estimation, they should do the calculation procedure (algorithm) from the first until the end to determine whether the answer is right or wrong.

Since there are many mathematics problems in the form of calculation estimation (incorrect calculation), it is reasonable that calculating estimation should be introduced in the school. Nevertheless, generally, the primary school has not paid attention to it. Through observation and dialogue with the teachers and headmaster in Primary School of Kedungkandang 01 Malang and at that time the researcher (the author) guided the undergraduate student of PGSD in KPL program, he got the information that the lesson of estimation had been never taught explicitly in the learning since it did not exist in the learning program of the primary school. Furthermore, from the interview with some students in the school, he got the information that the students feel complicated (with themselves) to determine the estimation result. This case happened since they did not think about estimation especially before. Moreover, estimation is unavailable in the mathematics books of primary school; they felt that they did not complete estimation problems and the questions needing the reason for the answer before. The students usually do and complete the mathematics items based on the rules or particular procedures (algorithms). Computational estimation is viewed as perhaps the most neglected skill area in the mathematics curriculum Reys, at all [7].

Hibert [8] in his research states that more than a half of thirteen years old children gave answer 19 or 21 in the estimation item of summation of two fractions closing one " $(12 / 13+7 / 8)$ ". The author also got the same results when he did the exploration test in class VI of Primary School of Kedungkandang 01 Malang and the item was " $(13 / 14+8 / 9)$ ". The analysis results show that more than $62 \%$ of students answered 21 or 23 . This phenomenon is because the students' conceptual and procedural knowledge are isolated causing both of them do not correlate with each other [8]. Whereas, the students who have understood the fractional concept and the procedure to do it, the result of both fractional multiplications above is close to 2 since each of fraction is close to 1 .

Based on the explanation above, a learning approach is needed to enhance the mastering level of calculating estimation skill. Therefore, the author is willing to do an action research, that is "Enhancing the Calculating Estimation Skill of the Students of Class VI in the Primary School of Kedungkandang 01 Malang through Benchmark."

\section{METHOD}

This study used a qualitative approach. The use of such an approach aimed to investigate and get clearly the description of phenomena during the learning process such as the class situation and the students' attitude. The type of qualitative research used was collaborative class action research. Such type enables the cooperative work between the class teacher and lecturer, increases the learning practice, contributes to the theory development as well as improves the teacher's performance. Teacher and lecturer from a college have a partnership relationship so they can meet together to think about the problems that are going to study.

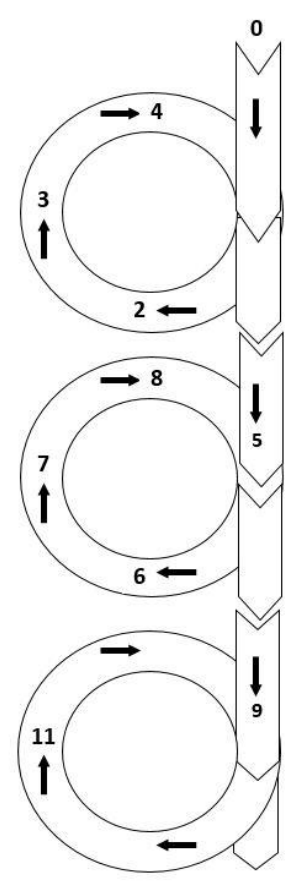

$$
\begin{aligned}
& \text { Note: } \\
& 0=\text { first reflection } \\
& 1=\text { action planning } \\
& 2=\text { action I } \\
& 3=\text { observation I } \\
& 4=\text { reflection I } \\
& 5=\text { revised planning } \\
& 6=\text { action II } \\
& 7=\text { observation } 2 \\
& 8=\text { reflection } 2 \\
& 9=\text { revised planning } \\
& 10=\text { action III } \\
& 11=\text { observation } 3
\end{aligned}
$$

Fig. 2. Scheme Of Thinking And Reading In Critical Literacy

In this research, the researcher and teacher acted as an observer and actor (teacher in the learning process) in turn. Subsequently, all results of observation were discussed together and noted in a daily journal of the researcher. The results of observation and interview with the researched subjects were used to reflect the activities done repeatedly to take a conclusion based on the focus of the study.

The analysis model used in this research consists of three activities conducted in order; they are data reduction, data presentation, taking conclusion and verification. This research was conducted in the three cycles of which each consists of four stages including planning, implementation, observation, and reflection. This case is in line with the opinion of Kemmis and Mc Taggart [9] stating that the model of an action research is in the form of Spiral as presented in Fig.2. 
The result of observation, analysis, and reflection of $\mathrm{Ib}$ action, we got the information that during the learning, the five subjects looked motivated. This case was shown by their responses to the questions asked by their teacher. The discussion among the students was getting well, and the students started to ask problems they did not understand. Based on the result of the formative test of $\mathrm{Ib}$, all subjects seemed to be able to determine the estimation results by finding the benchmark and giving the reason for their estimation. Thereby, the goal of learning to help the students'difficulties in doing the estimation of count number only has been accomplished.

Cycle II consisted of two learning actions: IIa and IIb. The learning activity in cycle II was begun with learning action of IIa. From the result of observation, analysis, and reflection in the IIa action, we got the information that WY and IF were good in estimating by using benchmark and arguing the reason. Meanwhile, $\mathrm{WD}, \mathrm{AB}$, and $\mathrm{CD}$ were still confused in understanding the big or small fractional number and its correlation to the calculation operation. $\mathrm{AB}$ and $\mathrm{CD}$ still said that if fractional numbers were summed they should equate the denominators first and then they were summed. WD had tried to find the benchmark, but he still got difficulty in finding the appropriate benchmark so the estimation result determined was not based on the proper reason.

Based on the explanation above, we can say that the aim of the learning activities of IIa did not maximally succeed. This case was proven by the students who could not estimate the fraction form well. Therefore, there should be the repetition of learning action (IIb) by focusing on the great understanding of fraction and the equivalent fractions to reach the determined goals.

From the result of observation, analysis, reflection and formative test of IIb, it was found that the five students were serious and highly motivated in following the lesson. This phenomenon could be seen through the learning process from the first part until the end; even they unnoticeably spent the time. In determining the estimation result with the benchmark, all subjects were good. This case can be seen through the information or explanations given by the researched students in the interview. Thereby, the goal of learning activities of IIb was successful; every researched subject could determine the estimation result and delivered the reason well. Moreover, the effort of enhancing the students'skill in estimating related to a fractional number by finding the benchmark and giving the reason for the estimation result is considered as enough.

In cycle III, there was only one action, that was IIIa action since all students had been familiar with the benchmark. From the results of observation, analysis, and reflection of IIIa action, it was found that the five researched subjects could estimate any calculation well by finding the benchmark first and giving the reason for the estimation well. From the results of the interview, the students could give argumentation and answer for the estimation they have done well enough as well. Thereby, we can say that learning as an effort of the student to estimate particular calculation that contains decimal number only and give the reason for the estimation result that has been successfully conducted.

After giving the formative test in IIIa, the final test was given as the last test of all actions to know the influence of express their ways of thinking to estimate the certain form of calculation. Therefore, Ib action should be conducted subsequently. 
learning actions of Ia, Ib, IIa, IIb, and IIIa as well as to know the progress of students in estimating by finding the benchmark. From the result of the students' task (the final test of all actions), it was found that they have found the benchmark in estimating the calculation. Furthermore, they also can write down their ways of thinking well to get a result in the form of estimation.

\section{DISCUSSION}

\section{A. Action Cycle I}

The learning conducted in this cycle is in an attempt to enhance the students'skill in estimating any calculation containing count number. In this case, the students were led to be able to estimate the certain form of calculation by finding the benchmark. The learning activities in this cycle were conducted twice; they were Ia and Ib.

In the learning activities of Ia, the effort was begun by giving appreciation about the estimation generally, and it was continued by calculating estimation. The estimation learning was started by proposing a certain problem, then the students were asked to understand the problem. After the students said that they had understood the problem, it was continued by discussion between teacher and students since through this discussion, it was expected that the students could express their thought about estimation and their ways of thinking. Besides, through this discussion, it was expected that the students could increase their knowledge through the questions delivered by their friends, so they were trained to communicate mathematics. The importance of mathematics communication is stated by Kennedy and Tipps [10] saying that one of the important goals in mathematics learning is helping the student communicate mathematics. This case is because almost all the problems in the technology era need mathematics so the skill in communicating it is significant.

Communication between teacher and students is oriented to the students'skill in expressing reason for the estimation since this particular skill is essential in understanding mathematics. The students can see that mathematics is meaningful by developing their ideas, exploring the phenomena, assessing the results and using the math conjecture [11].

In the discussion between teacher and students, the students seemed reluctant to deliver their thought and sometimes they answered after the teacher repeated the question. Nevertheless, the teacher always tried hard to make them were willing to speak up their mind. After discussing the problems performed by the teacher and the students, they were asked to discuss estimation together. For this activity, the students were given LKS (Students Activity Sheet). They were then asked to discuss with each other before answer the question given. In this part, the students seemed reluctant to express their opinion as well although the teacher had tried hard to motivate them to discuss with each other in solving the problems. By seeing this phenomenon, the teacher attempted as maximum as possible to make the students were willing to discuss so they could broaden their knowledge by getting a suggestion, critics, and solution from their friends in a group. After much effort, a little bit was changing of the students; they started to venture to ask and speak up their mind.
In a group discussion, the teacher guided the students to achieve the expected goal that is the students can estimate the calculation models containing only count number by finding the benchmark and give the reason of the estimation. The learning in the Ia action mainly emphasized on the discussion between the teacher and students in a group consisting of five people to encourage the students to estimate and express their opinion. Nevertheless, the results were not maximum yet. This result based on the result of the formative test of Ia and interview with each students showing that not all of the researched subjects could estimate and give the reason for the estimation well. $\mathrm{AB}, \mathrm{WD}$, and $\mathrm{CD}$ were quite difficult in performing their ways of thinking to estimate a certain model of calculation, while IF was incomplete in explaining the reason and WY seemed good enough in delivering the reason.

Based on the explanation above, the learning action was continued by $\mathrm{Ib}$ action. Ib action used speech, discussion and giving the test to a small group as a method. If in Ia action, the task was paid to the group consisting of five students, while in $\mathrm{Ib}$, the students were divided into small groups consisting of two or three students. The small group was aiming at maximizing the discussion among the students especially for the step of telling, that was one or two students spoke their thought, the ways to solve the problem freely, and their ideas were expected to increase their skill in performing discussion in a bigger group.

From the results of observation, formative test and interview, it was found that by giving task in a small group can enhance the students' skill in estimating and giving the reason. From the result of the interview particularly, the students were good enough in delivering their ways of thinking about the estimation. The skill in giving systematically the reason and the way of thinking are the primary targets of standard as Carpenter \& Grog [11] state that:"Ambitious Standart is required to achieve a society that has the capability to think and reason mathematically."

From the result of thinking and giving the reason, mathematics can be communicated to the students. Communication is an essential thing in mathematics education; it is one of the ways of delivering the ideas and understanding. The ideas can be reflected, emphasized on, discussed and changed through communication [11].

\section{B. Action Cycle II}

The learning activities in this cycle are to enhance the students'skill in estimating and reasoning to the estimation of fraction number. In this case, the students were asked to find the estimation patterns enabling the benchmark originated from the fraction. The learning activity in this cycle was conducted two times; they were IIa and IIb actions.

In the IIb action, the teacher attempted to activate the students in discussion to be able to express their thought about estimation and also to develop their skills in communicating mathematics. Besides, as the essential part of mathematics, mathematics communication is important in the social life in this technology century. This case is in line with Kennedy \& Tipps [10] stating that the technology society today depends on the computer and other tools receiving, manipulating, saving and sending data and ideas. The individual who is lack of understanding and skill in 
using such tools will not be able to compete in business, scientific, government, medical and other social community.

The learning was started by proposing a problem of fraction summation and the students were asked to estimate it. The result of a discussion between teacher and students showed that WY could find the benchmark first to determine the estimation result while the other students could not find it. They still were stuck to the procedures of fractional summation usually used. For example, if they want to sum up a fraction model, they should equate the denominator first, and after that, the numerator is summed up, and the denominator is not summed up. This result is a summation of two fractions. We can see that the students had not understood the amount of fraction and seen the correlation between fraction and count number. The students just assumed that a fraction consisted of numerator and denominator. Such thought caused them were difficult in estimating.

After the dialogue between teacher and students, the activity was continued with the discussion of students in a small group by discussing the questions proposed. This kind of small group is good to improve the students' skill in communicating mathematics in the first stage. This case is because they only faced one or two friends so they felt relax and they dared to tell their ideas although they usually seemed reluctant to deliver their opinion.

After the students had been sure with the result of the discussion with one or two friends, they were asked to share the results with other groups to improve the mathematics communication. This activity can stimulate the students' confidence as well since they do not deliver their opinion in front of many people directly, but they can prepare and confirm first their views to one or two friends.

Although in IIa the students seemed developed in communicating mathematics (in the case of estimation), based on the results of students' tasks and interview, the learning in attempting to enhance the students' skill in estimating calculation consisting fraction models was not optimal yet. From the results, WD, CD, and AB had not understood well the amount of fraction. Their understanding was still stuck to the numerator and denominator but they had not understood the substance of the fraction related to the type of number especially count number.

Based on the explanation above, the learning activity was continued by IIb action. In IIb learning action, the students were given a model tool "Cuisenaire rod" for every small group. The aim of providing such tool conceptually and in fact is the students can understand well the relationship of a fraction with the number of $0,1 / 2,1$, and the equivalent fraction. For example, $1 / 12$ is closer to 0 (zero), 5/12 is less to $1 / 2,11 / 12$ is close to $12 / 12$ or 1 (one). After that, the students were led to the fraction understanding illustrated by "number line" for a fraction with a bigger denominator (the smaller fraction).

The students were getting more active in learning mathematics by using such a model tool since they had understood well the fraction concept. The result was the students could determine the big or small amount of fraction, the equivalent fraction and compare two fractions as well as the correlation of certain fraction to the common fraction (a simple fraction and the calculation was done mentally).
The focus of IIb learning action was on the conceptual approach continued by the procedural approach and it was oriented to the constructivism since basically, it was to build an understanding. This case is affirmed by Willis Judi [12] stating that the process of understanding building is more important than the study result since the understanding is meaningful to the learned lesson.

After the learning activity in IIb had finished, the students were given exercise in a small group. In this case, the students were asked to enhance their communication skill by telling their opinion of each other in the small group. The students were then given the final test (formative test of IIb). From the results of students' tasks and interview with all researched subjects, the students seemed could estimate the calculation models containing a fraction. Their skill in using benchmark in estimating was getting better. They could see the fraction model flexible, and its correlation to other numbers especially count number.

\section{Action Cycle III}

The learning at cycle III is an effort to enhance the students' skill in estimating calculation model enabling the benchmark resulted from decimal. In this case, the students were led to be more critical in examining the numbers as the benchmark of a decimal.

The result can be achieved in one action to reach the determined goal. In this III action, the teacher gave two problems related to the decimal number. One of them was related to the logic of certain calculation result. The teacher did a dialogue with the students to discuss it. During the dialogue, all students were asked to think in determining the answer so they could compare their friends' opinion and their thought.

In this dialogue, the students were led to find the benchmark from the decimal number to estimate without sticking to the procedure of summation or multiplication containing decimal (especially in multiplication) since the procedure positioning coma at the result of multiplication after certain number based on the amount of number behind the coma of the numbers multiplied would be confusing. The confusing one is especially if the multiplication resulted in some zeros at the end (wherever and however the zero number behind the coma is nothing at all, and it can be deleted). The estimation pattern embedded to the students will enable them not stick to the pattern of putting coma based on the procedure that is sometimes confusing, but the orientation is to the amount of number.

After the dialogue between teacher and students had finished, the students were given LKS to be completed in a small group. The results of the observation, the discussion among the students was getting alive. This situation was definitely different from the discussion in the previous actions. In this cycle, every student seemed active in asking, delivering an opinion, giving suggestion and critics. During this discussion, the teacher as a facilitator always supervised and assisted the students. To end the learning, the teacher gave formative test III containing estimation items with decimal numbers. From the result of students' tasks, the students could estimate and gave the reason well. This case was emphasized by the results of the interview since it is hard to conclude whether they had understood the lesson well only from what they had done. 
After the three actions (I, II, and III actions) had ended, the students were given the final test of all actions including all lessons discussed (count, fraction, and decimal numbers). From the result of the very last test, we can say that the students had been able to find the benchmark in estimating. In addition, they could write down and express their ways of thinking well. And there is progress in learning math through benchmarks, such as those in Taiwan [13]

Based on the result of this research, the researcher suggests some recommendations as follow:

- The teachers of primary schools are recommended to insert estimation lesson in every opportunity since more than $80 \%$ of mathematics applications are related to calculation and the calculation estimation more beneficial rather than the exact calculation.

- In the implementation with the motto of "estimation is a skill for life," the teachers are recommended to ask their students to estimate the result of a certain calculation before they calculate the exact one so the possibility of being an error in calculating can be detected quickly.

- The class teacher (especially mathematics teacher) is recommended to control continually whether the calculation results of the students are meaningful for them in the order they do not only work with a procedure that actually it is not meaningful to them. One alternative that can be done by the teachers to enhance the students' calculation estimation skill is by leading the students to find the benchmark in estimating.

- The teachers are recommended to habituate the students to calculate mentally (do not always use algorithm) so they can quickly step to the estimation. Yea-Ling Tsao, et al. [14].

\section{CONCLUSION}

Generally, the students did not have a particular estimation pattern but based on the research findings, the students' understanding of estimation can be concluded as follow. For count number, the students' understanding of estimation is calculating with the right answer by using procedure and then rounding it to tens or hundreds...even the closest hundred thousand. The students understood the result of this rounding as estimation.

For a fraction, the students were stuck to the procedure of summation and multiplication of fraction. When they were asked to estimate for summation, they always thought that the denominator should be equated first and then it was calculated. For decimal, similar to count and fraction numbers, the students still could not leave algorithm to estimate. They calculated first based on the procedure; they then rounded it into the closest tithing or percent. Sometimes, after they calculated by using algorithms, the number behind the comma was deleted, and they said that the number behind the count number was the estimation result.

The students underwent some difficulties in estimating such as (1) they did not have particular strategy to estimate; (2) they had not understood the amount of certain number flexibly; (3) calculating for the students was only determining one targeted right answer by using algorithms; (4) they had not understood the meaning of fraction comprehensively and its correlation to the summation and multiplication operations; and (5) especially for decimal multiplication, the students were still stuck to the procedure of decimal multiplication in which the numbers behind comma as the result of multiplication was as many as the number behind comma of the numbers multiplied.

We can do some treatments to enhance the students' estimation such as (1) leading the students to find the benchmark of the numbers used in the calculation by examining the meaning of every number deeply through discussion; (2) leading the students to understand the problems well by reading and comprehending it; (3) changing the paradigm that the tool used to calculate is not only by using the standard procedure but also by using estimation in certain context; (4) Activating discussion between teacher and students so their estimation skill can increase; (5) activating discussion in a small group in order the mathematics communication among them runs well so they feel that mathematics does not deal with the only number but also it is a kind of communication media (language), and (6) asking the students to write down the reason of every estimation result so they are trained to deliver their thought

\section{REFERENCE}

[1] Post, T. R. 1992. Teaching Mathematics in Grade K-8. Massachusetts: Allyn and Bacon

[2] Reys, R.E., Lindquist, M.M., Lambdin, D.V., Smith, N.L. 2015. Helping children learn mathematics. Australian: Wiley.

[3] Walle, Van de J A. 2013. Elementary and Middle School Mathematics: Teaching Developmentally. (8th/e) (Pearson New International Edition)

[4] Barry Lewis. 2014. Help Your Kids with Math. USA: DK. Publishing

[5] Sinnakaudan S, Hashim S and Ghazali M. 2017. Calling for the development of children's number sense in primary schools in Malaysia. International Journal of Primary, Elementary and Early Years Education. Vol. 45.

[6] Bennett Jr, AB \&, Nelson LT. 2007. Mathematics for Elementary Teachers (7th/e) - A Conceptual Approach. New York: McGraw-Hill.

[7] Reys, at All.1982. Processes used by good estimators. Journal for Research in Mathematics Education. Vol 13 (3).

[8] Hiebert, J. 2016. Conceptual and Procedural Knowledge: The Case of Mathematics. Taylor \& Francis.

[9] Kemmis T \& Mc. Taggart. 2014. The Action Research Planner. (Doing Critical Participatory Action Research). USA: Springer.

[10] Kennedy \& Tipps. 2011. Guiding Children's Learning of Mathematics, edition 12th. Thomson Wadsworth.

[11] Carpenter, J. Dan Grog, S. 2000. Principles and Standards for School Mathematics. Reston: NCTM, Inc.

[12] Willis Judi. 2010. Learning to Love Mathematics -Teaching StrategiesThat Change Student Attitudes And Get Result : Virginia: Alexandria.

[13] Der-Ching Yang \& M. L. Lai. 2013. Teaching Benchmark Strategy for Fifth-Graders in Taiwan. Journal of Education and Learning; Vol. 2, No. 2. Published by Canadian Center of Science and Education.

[14] Tsao, Y. L., \& Pan, T. R.. 2013. The Computational Estimation and Instructional Perspectives of Elementary School Teachers. Journal of Instructional Pedagogies, 11 